\title{
Free Radical scavenging activity of Fagopyrum esculentum Moench. Seed and seed protein concentrat esextracted by different procedures
}

\author{
Nidhi Gupta*, A. K. Srivastava and V.N. Pandey \\ Experimental Botany and Nutraceutical Laboratory \\ Department of Botany DDU Gorakhpur University Gorakhpur-273009.
}

\begin{abstract}
Fagopyrum esculentum Moench (Buckwheat) is a nutritionally important pseudocereal because of its high protein content and balanced essential amino acid profile. In the present study, the seed sample and seed protein concentrates (SPCs) of Buckwheat extracted by different procedures were tested for their antioxidant activity by DPPH free radical assay. The maximum free radical inhibition by crude seed extract at concentration $100 \mu \mathrm{g} / \mathrm{ml}$ was found $78 \%$. However, the Lactobacillus fermented SPC shown $73 \%$ inhibition. A comparative antioxidant capacity of SPCS were also studied and the maximum antioxidant activity $(73.10 \%)$ was recorded in Lactobacillus fermented SPC followed by coagulation at pH 4.5 (68.35\%) while minimum (62.54\%) was found in heat coagulated SPC.

The study indicates that crude seed extract showed higher radical scavenging activity than SPC. On the other hand, the Lactobacillus fermentation of SPC raises the antioxidant activity while this property decreases at high temperature.
\end{abstract}

Key Words: DPPH assay, Buckwheat, Seed extract, Seed protein concentrate (SPC), Coagulation procedures, Antioxidants.

\section{Introduction}

Free radicals are reactive oxygen species with unpaired electrons, derived from the metabolism of oxygen and, are often generated as byproducts of biological reactions or from exogenous factors. These reactive oxygen species are hydrogen peroxide, hydroxyl radical, nitric oxide, pernitrite, singlet oxygen, peroxyl radical and superoxide anion (Subhasree et al.,2009). Oxidative stress has been shown to be one of the mechanisms that correlated with oxidative damage caused by the over production of free radicals leading to chronic diseases like cancer, coronary heart diseases, diabetes, neurodegenerative diseases and even ageing (Liu et al., 1999; KrisEtherton et al.,2002). Mammalian cells possess elaborated defence mechanism for radical detoxification; however, exogenous sources of antioxidants are also required. Antioxidants refer to the compounds which have the ability to repair damage or inhibit the oxidation of biomolecules by inhibiting the initiation or propagation of oxidative chain reactions and thus capable of counteracting the damaging effects of oxidation in biological system (Finkel \& Holbrook, 2000). These compounds may be an enzyme, metabolite or other phytochemical substances in foods that significantly decreases the adverse effects of reactive species, such as reactive oxygen and nitrogen species, on normal physiological function in humans. Epidemiological studies have shown that many phytonutrients of vegetables, fruits, legumes, cereals as well as wholegrains might protect the human body against damages by reactive oxygen species (Zielinski \& Kozlowska, 2000; Andlauer and Frust, 2002). The health promoting quality of fruits and vegetables are attributed to the presence of dietary antioxidants, including polyphenolic compounds, Vitamins (E and C) and Carotenoids that are believed to be the effective nutrients in the prevention of the oxidative stress related diseases (Kaur and Kapoor, 2002). The consumption of foods containing antioxidants will thus offer protection against these diseases.

Fagopyrum esculentum (Buckwheat)is a traditionally used pseudocereal plant belonging to familyPolygonaceae. The plant is herbaceous broad leaved growing naturally as well as cultivated for their grains to be consumed in human diet. Seeds are known to contain various phytochemical compounds with antioxidative properties, such as Vitamin $\mathrm{B}_{1}, \mathrm{~B}_{2}$, and $\mathrm{E}$, phenolic compounds viz. as rutin, quercetin and proanthocyanidines (Watanabe et al., 1997; Przybylski et al., 1998). The presence of bioactive compounds and phytochemicals in the plants are correlated with multiple biological effects including high nutritional quality and antioxidant activity. Therefore, the antioxidant capacity of seed extract and seed protein concentrates was determined by DPPH free radical scavenging assay.

\section{Materials and methods}

2.1Chemical used:0.1N-Hydrocloric acid, Sodium chloride, Acetone, Alcohol, ethanol, methanol, 1, 1Diphenyl-2-picrylhydrazyl (DPPH) and Butylated Hydroxyl toluene (BHT) were all of analytical grade. 


\subsection{Collection and Identification}

Seeds of Fagopyrum esculentum Moench. (Buckwheat) collected fresh from field and stored seeds from market. Identification of plants, whenever needed was done with the help of Srivastava (1976) and confirmed by consulting the experts and Herbarium of the Department of Botany, DDU Gorakhpur University, Gorakhpur, India. The plant fruits/ seeds were sun dried, the dry seed sample were blended by using pestle and mortar after which the powdered sample were weighed.

\subsection{Seed Protein Concentrate (SPC) Extraction}

The SPC was extracted by the method of Molina and Bressani (1973). Six (6) g of seeds were homogenized with $200 \mathrm{ml}$ double distilled water in a waring-blender for 30 minutes. The homogenate was filtered through double layered muslin cloth to remove the fibrous material. $0.1 \mathrm{~N}-\mathrm{HCL}$ was added to the filtrate slowly with constant stirring to give a final $\mathrm{pH}$ of 4.5 (isoelectrical $\mathrm{pH}$ ) for coagulation of SPC. The coagulated protein was filtered through Whattman filter paper No. 1.

The other methods of seed protein coagulation are heating at natural $\mathrm{pH}$, fermentation by Lactobacillus lactis and addition of a common salt $(\mathrm{NaCl}$,). For coagulation by fermentation through Lactobacillus lactis, was added to $100 \mathrm{ml}$ of extract which was incubated at $30^{\circ} \mathrm{C}$ for $12 \mathrm{~h}$. Coagulation by addition of salt was carried out by adding requisite amount of sodium chloride $(0.5,1,2,3,5$ and $10 \mathrm{~g} \mathrm{w} / \mathrm{v}$ separately) to the extract which was kept for $2 \mathrm{~h}$ for coagulation. The dried protein concentrate was subjected to grinding to make it fine powder which is used for further experiments.

\subsection{DPPH radical scavenging Assay}

One g of Seed powder and SPCs (Seed Protein Concentrates) was mixed in $30 \mathrm{ml}$

of methanol and homogenized in a blender. The crude extracts were filtered and concentrated using rotatory evaporator. After recovery of the homogenate, $15 \mathrm{ml}$ methanol was used to wash the blender and then pooled with the first homogenate. The mixture was centrifuged at $4500 \mathrm{rpm}$ for $15 \mathrm{~min}$ at room temperature. Filter the supernatant and made the volume up to $50 \mathrm{ml}$ with methanol. DPPH assay was done by the method of Oktay, et al. (2003). The $0.1 \mathrm{mmol} / \mathrm{L}$ solution of DPPH was prepared in the methanol and $1 \mathrm{ml}$ of this solution was added to $3 \mathrm{ml}$ of seed extract/SPC extract solution at concentrations of 10 to $100 \mu \mathrm{g}$. The tubes were shaken vigorously and allowed to stand for $20 \mathrm{~min}$ at room temperature. A control was prepared as above without any sample and methanol used for base line correction. Changes in the absorbance of samples were measured at $517 \mathrm{~nm}$. Lower absorbance of the reaction mixture indicated higher free radical scavenging activity, which was expressed as inhibition percentage and was calculated by using the formula:

$\begin{gathered}\text { Radical Scavenging } \\ \text { Activity }\end{gathered}=$

$$
\text { Control O.D. - Sample O.D. }
$$

\subsection{Statistical Analysis}

All statistical analysis was done by Polo plus 2.0 Software. The data were subjected to Statistical analysis by using Polo Plus 2.0 software to determine the $\mathrm{IC}_{50}$ value of methanolic extract for free radical inhibition. The curve for $\mathrm{IC}_{50}$ was plotted by using logit model.

\section{Results}

The methanolic extract of the Buckwheat seed and SPCs at different concentrations ranged from 10 to $100 \mu \mathrm{g} / \mathrm{ml}$ were tested for their ability to scavenge free radicals by in-vitro systems (DPPH assay). The percentage inhibition for each concentration and $\mathrm{IC}_{50}$ values of the extracts were calculated. All the experiments were done in triplicate and statistical analysis was also used to determine the mean value across the concentration range for each assay, to facilitate the comparison of the free radical-scavenging activities of the methanolic extracts of pulverized seed sample and Seed Protein Concentrates (SPC) of Buckwheat.

DPPH radical scavenging activity of seed sample (Fig-1) and SPC of Fagopyrum esculentum at different concentrations represented in Fig.2. The maximum free radical inhibitions were $78 \%$ and $73 \%$ in methanolic extract of seed and SPC of Fagopyrum esculentum respectively at concentration $100 \mu \mathrm{g} / \mathrm{ml}$. the $\mathrm{IC}_{50}$ value for methanolic seed extract and methanolic extract of SPC were calculated $58.94 \mu \mathrm{g} / \mathrm{ml}$ and $66.06 \mu \mathrm{g} / \mathrm{ml}$ respectively. A comparative study of DPPH radical scavenging activity of methanolic extract of seed and SPC shown in fig-3. The DPPH radical scavenging activities of Seed Protein Concentrates (SPCs) extracted by different procedures viz. heat coagulation $\left(60^{\circ} \mathrm{C}\right)$ at natural $\mathrm{pH}$, coagulation at isoelectrical $\mathrm{pH}(\mathrm{pH} 4.5)$, Lactobacillus fermentation and salt $(\mathrm{NaCl} 2 \% \mathrm{w} / \mathrm{v})$ were given in Fig-4. The maximum per cent inhibition of DPPH radical was observed in Lactobacillus fermented SPC i.e. $73.10 \%$, followed by coagulated at $\mathrm{pH} 4.5$ 
$(68.35 \%)$, and salt coagulated SPC $(66.80 \%)$ while the minimum radical scavenging activity $(62.54 \%)$ was observed in heat coagulated at natural pH SPC of Fagopyrum esculentum.

\section{Discussion}

The Biomolecules which have ability to repair the damage caused by free radicals and to reduce the risk of cancer, neurodegenerative diseases, cell membrane damage, cardiovascular disease, autoimmune disorders, ageing, apoptosis etc are called antioxidant (Simonian and Coyle, 1996). Antioxidants produced within the body include dismutase, peroxidase and catalase enzyme, as well as glutathione (GHS) and cytochrome $\mathrm{P}_{450}$. Some of these compounds are exogenous in nature and are obtained from natural foods.

Natural antioxidants include phenolic compounds, tannin, flavonoids, carotenoids, anthocynins, vitamin-C, Vitamin-E etc. They have a wide range of biochemical activities, including inhibition of reactive oxygen species (ROS) generation, direct or indirect scavenging of free radicals, and alteration of intracellular redox potential (Prakash et al., 2007; Gupta and Prakash, 2009). Rice et al.,1995 studied the antioxidant activity of plant derived compounds like flavones, polyphenols, flavonoids and advocated the food based strategies for amelioration of disease simply by improving the dietary intake of nutrient with antioxidant properties. Synthetic drugs for the treatment of diseases can be very expensive due to which providing modern healthcare to rural people is still a far-reaching goal (Grover et al., 2002). This compelled the food scientist and industries to develop antioxidant phytochemicals rich functional foods. Andlauer and frust (1998) focused on this challenge, especially in relation to cereals and whole grain products. Several studies indicated the beneficial role for wholegrain intake in reducing the risk of coronary heart disease, diabetes, hypertension and some types of cancer (Ascherio et al.,1992; Andlauer and frust, 1998). Vinson et al., 2001 observed phenolic antioxidant quantity and quality of foods.

This radical scavenging assay is one of the most widely used methods for screening the antioxidant activity of plant extracts. The DPPH method allows a direct investigation of the ability for the extract or antioxidant to donate hydrogen and/or electron to quench the DPPH radical (Bandet et al.,1997). The assay is based on the measurement of the antioxidant ability to scavenge the radical DPPH. The DPPH test shows the ability of the test compound as an antioxidant and to act as a free radical scavenger. DPPH is a free radical and it produces a strong absorption band at $517 \mathrm{~nm}$, in the visible region of the electromagnetic radiation. DPPH radicals react with suitable reducing agents, during which the electrons become paired off and solution loses colour stoichiometrically depending on the number of electron taken up (Blois, 1958). In the experiment, the solution progressively reduced to a yellow coloured product, di-phenylpicryl hydrazyl, with the addition of the extracts in a concentration- dependent manner.

In the present study, the DPPH free radical scavenging activity of the seed extract and Seed Protein Concentrates obtained by different procedures ranged between $62.54 \%$ to $78.0 \%$. Fig. 1 and Fig-2 represents DPPH free radical scavenging activity of seed sample and SPC respectively. The free radical inhibition activity of pulverized seed sample was found dose dependent. $\mathrm{An}_{\mathrm{IC}} \mathrm{C}_{50}$ value is the concentration of the sample required to scavenge $50 \%$ of the free radicals present in the system. The $\mathrm{IC}_{50}$ value of methanolic extracts of the seed and SPC indicate the ability of seed extracts to scavenge $50 \%$ free radicals. For DPPH radicals the $\mathrm{IC}_{50}$ value of the methanolic seed extract is $58.94 \mu \mathrm{g} / \mathrm{ml}$ and $66.06 \mu \mathrm{g} / \mathrm{ml}$ for that of SPC extract. The lower the $\mathrm{IC}_{50}$ value, the higher the free radical scavenging activity. In present study the $\mathrm{IC}_{50}$ value $(58.94 \mu \mathrm{g} / \mathrm{ml}$ and $66.06 \mu \mathrm{g} / \mathrm{ml})$ is lower than the lowest value $(1.3 \mathrm{mg} / \mathrm{ml})$ of wheat germ protein hydrolysate prepare with alacalase (Zhu et al.,2006) and the $\mathrm{IC}_{50}$ value (0.56 to $0.94 \mathrm{mg} / \mathrm{ml}$ ) of Buckwheat protein hydrolysate (Tang et al.,2009). Shubhasree et al.,2009 investigated the antioxidant potential of four leafy vegetables and reported the $\mathrm{IC}_{50}$ value for $\mathrm{DPPH}$ radicals ranged $85-435 \mu \mathrm{g} / \mathrm{ml}$. Oomah et al.,1996 worked on antioxidative properties and concentration of different antioxidant biomolecules in different varieties of buckwheat. Fig-3 represent a comparison between the free radical scavenging activity of methanolic extract of seed and SPC. The antioxidant ability of methanolic extract of seed powder was found greater at all concentration than those of the methanolic SPC extracts. Fig.4. shows the rate of free radical inhibition by SPC extracted by different procedure. The maximum free radical inhibition activity was observed in SPC extracted by Lactobacillus fermentation i.e. $73.10 \%$ while that of minimum was observed in heat coagulated SPC at natural $\mathrm{pH}(62.54 \%)$. The pattern of DPPH inhibition was the same for all samples which were dose dependent. Common Buckwheat pulverized seed sample possessed the highest percent inhibition. The findings of present investigation is comparable to the other previous workers Tang et al.,2009; Srivastava et al., 2009. Larrauri et al.,1997, 1998 studied effect of temperature during processing on free radical scavenging activity and observed a negative effect. Wary et al.,2009; Kullisaar et al.,2002 reported that Lactobacillus fermentation raised the antioxidant ability i.e., increased free radical scavenging activity.

Methanolic extract of seeds has a higher free radical scavenging activity as compared to seed protein concentrates (SPCs) of Fagopyrum esculentum. Process of extraction of SPC also affect the free radical scavenging activity. Higher percentage inhibition of DPPH was recorded for Lactobacillus fermented SPC i.e., 
$73.10 \%$ at a concentration of $100 \mu \mathrm{g} / \mathrm{ml}$. which is comparable to the highest value of chickpea protein hydrolysate obtained by alcalase digestion (Li et al.,2008).

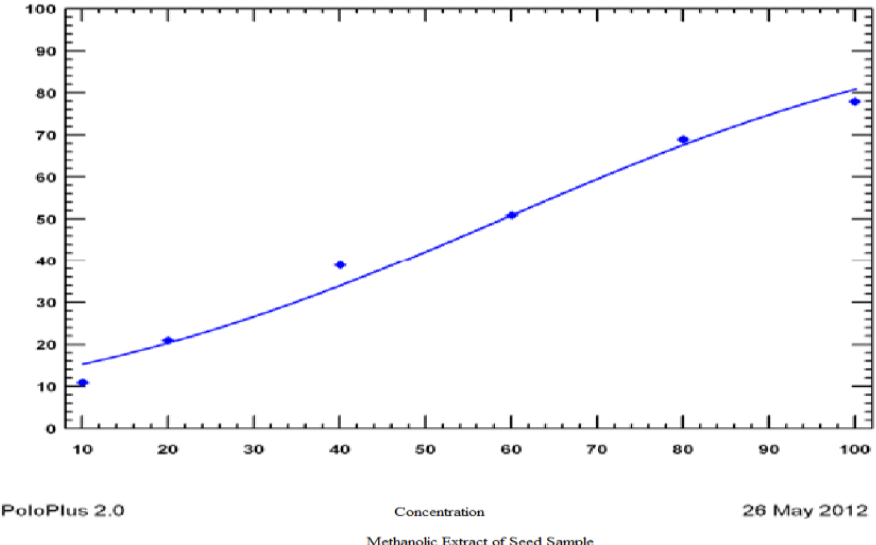

Fig-.1DPPH radical scavenging activity of seed sample. The value represents the mean of triplicates \pm S.E. for each concentration.

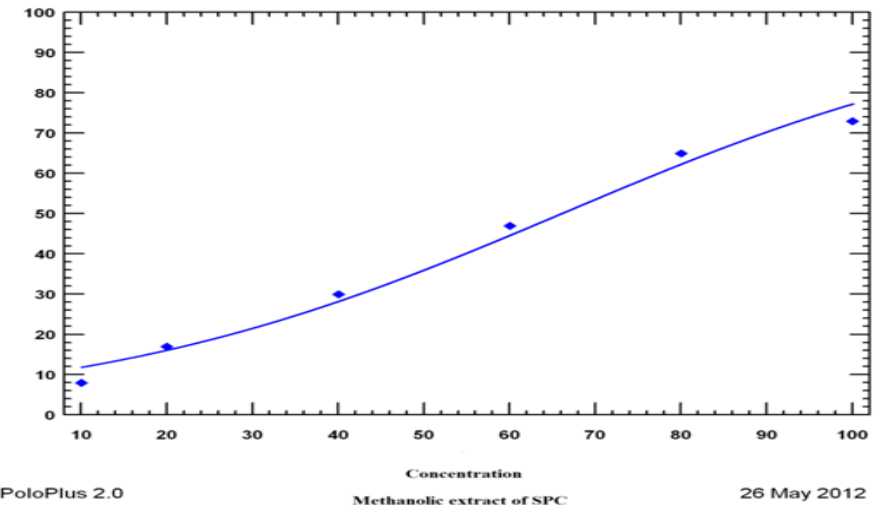

Fig 2: DPPH radical scavenging activity of SPC. The value represent the mean of triplicates + S.E. for each concentration.

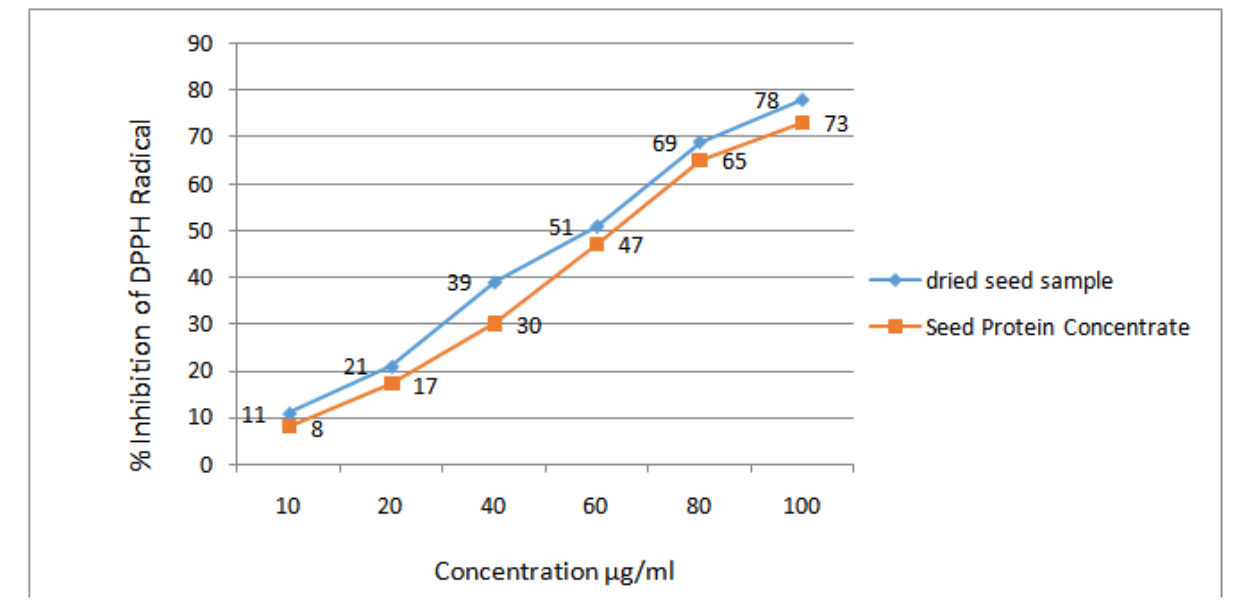

Fig 3: DPPH radical scavenging activity of seed and SPC of Fagopyrum esculentum Moench. The values represent the mean of triplicates + S.E. for each concentration. 


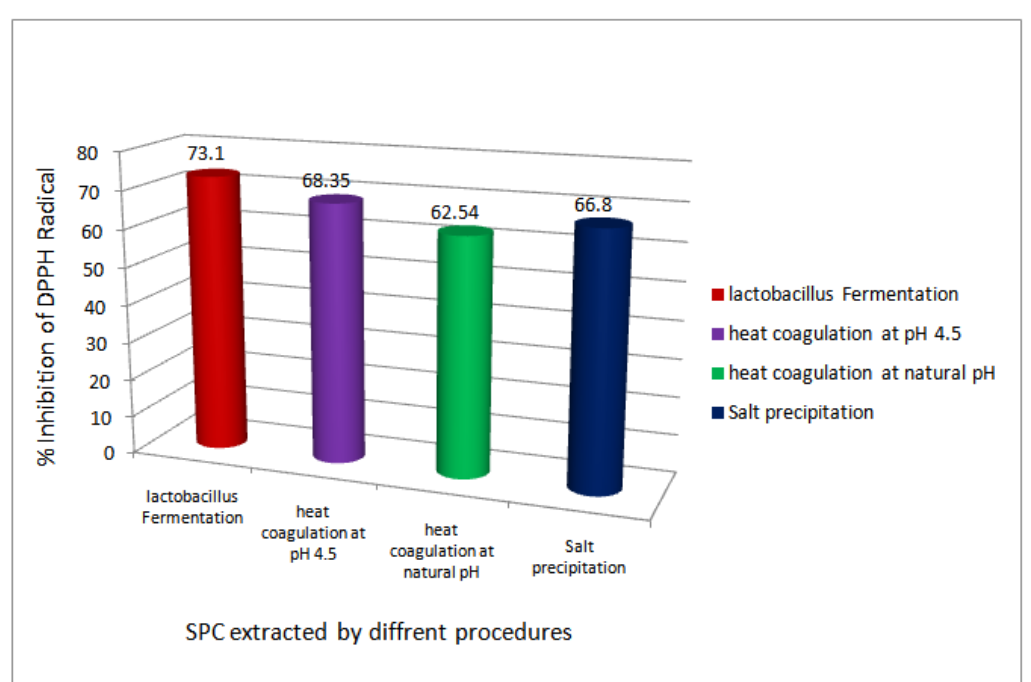

Fig 4: DPPH Radical Scavenging activity of Seed Protein Concentrate extracted by different procedures. The value represents the mean of triplicates $\underline{+}$ S.E. for each concentration.

\section{Conclusion}

The results obtained clearly indicate the methanolic extract of seeds contain high free radical scavenging activity compared to seed protein concentrates (SPCs) of Fagopyrum esculentum. Another investigation of the following experiment is that the Lactobacillus fermentation of SPC raises the antioxidant activity while this property decreases at high temperature. The conclusion of this study imply the enormous nutritive value of the Fagopyrum esculentum and their significance in the prevention of free radical-induced diseases.

\section{Acknowledgements}

The authors are thankful to Prof. Nisha Misra, Head Department of Botany D.D.U. Gorakhpur University, Gorakhpur, India for providing necessary facilities and State Council of Science and Technology, U.P. India, as well as Department of Science and Technology, New Delhi, India, for providing financial assistance.

\section{Reference}

[1]. W. Andlauer, P. Frust, Antioxidative power of phytochemicals with special reference to cereals, Cereal Foods World, 198, 43: 356360 .

[2]. W. Andlauer, P. Frust, Nutraceuticals: a piece of history present status and outlook. Food Research International,2002, 35:171-176.

[3]. Ascherio, E.B. Rimm , E.L.Giovannucci , G.A.Colditz,B. Rosner, W.C.Willet, F.Sacks,M.J. Stampfer, A prospective study of nutritional factors and hypertension among US men. Circulation,1992,86: 1475-1484.

[4]. Bandet ,W.Brand-William, C. Berset, Kinetics and mechanisms of antioxidant activity using the DPPH free radical method, Lebensmitted-Wissedschaft and Technology. Food Science and Technology, 1997, 30: 609-615

[5]. M.S.Blois, Antioxidant determination by the use of stable free radicals. Nature, 1958, 26: 1199-1200.

[6]. T. Finkel, N. J. Holbrook, Oxidant, oxidative stress and biology of ageing. Nature,2000, 408:239-247.

[7]. J. K. Grover, S. Yadav,V. Vats, Medicinal plants of India with antidiabetic potential. Journal of Ethnopharmacology, 2002, 81:81100 .

[8]. S. Gupta, J. Prakash, Studies on Indian green leafy vegetables for their antioxidant activity. Plant Foods for Human Nutrition, 2009,64: 39-45.

[9]. C. Kaur, H.C. Kapoor, Antioxidant activity and Total Phenolics content of someAsian Vegetables. Institute of Food Science and Technology 37(2) 2002,153-61.

[10]. P. M. Kris-Etherrton, K.D. Hecker, A. Bonanome, S.M. Coval, A.E. Binkoski, K.F. Hilport, Bioactive compounds in foods: their role in the prevention of cardiovascular diseases and cancer. American Journal of medicine, 113(9B),2002,71 S-88S.

[11]. T. Kullisaar, M. Zilmer, M. Mikelsaar, T. Vihalemm, H Annuk, C. Kairane, A. Kilk, Two antioxidative lactobacilli strains as promising probiotics. International Journal of Food Microbiology ,2002, 72: 215-224.

[12]. J. A. Larrauri,P. Ruperez, F. Saura-Calixto, Effect of drying temperature on the stability of polyphenols and the antioxidant activity of red grape pomace peels. Journal of Agriculture and Food Chemistry, 1997,45: 1390-1393.

[13]. J.A. Larrauri, C.S. Moreno, P. Ruperez, F. Saura-Calixto, Effect of Temperature on the Free Radical Scavenging Capacity of Extracts from Red and White Grape Pomace Peels. Journal of Agriculture and Food Chemistry, 1998,46:2694-2697.

[14]. Y. Li, Jiang B, Zhang T, Mu W, Liu J.. Antioxidant and free radical-scavenging activities of chickpea protein hydrolysate (CPH). Food Chemistry,2008,106: 444-450.

[15]. M. R. Molina, R. Bressani, Protein starch extraction and nutritive value of the jack bean (Canavalia ensiformis) and jack bean protein isolates. In Jaffe Werner G. (Ed.), Nutritional Aspectsofcommon beans and other legume seeds as animal and human foods Symposium. Ribeirao Preto, Brazil, III Archivos Latinoamericanos De Nutricion:Caracas, Venezuela. 6-9 Nov, 1973, 153-163.

[16]. M. Oktay, I. Culcin, O.I. Kufrevioglu,Determination of in-vitro antioxidant activity of fennel (Foeniculum vulgare) seed extracts; Labensmittel-Wissenschaft. Undertechnol, 2003,36: 263-271.

[17]. D. Prakash, G. Upadhyay,B. N. Singh, H. B. Singh, Antioxidant and free radical- scavenging activities of seeds and agri-wastes of some varieties of soybean (Glycine max). Food Chemistry, 2007, 104: 783-790. 
[18]. R. Przybylski, Y. C. Lee, N. A. M.Eskin,Antioxidant and radical-scavenging activities of buckwheat seed components. Journal of AmericanOil Chemistry society, 1998,75: 1595-1601

[19]. B. D. Oomah,C.Mazza,Flavonoids and antioxidative activ ties in buckwheat. Journal of Agriculture and Food Chemistry, 1996,44:1746-1750.

[20]. C. A. Rice-Evan, N.J. Miller, P.G. Bolwell, P.M. Bramley, J.B. Pridhan, The relative antioxidant activites of plant derived polyphenolics flavonoids. Free Radical Research, 1995, 22:375-383.

[21]. N. Y. Simonian, L.T. Coyle, Oxidative stess in neorodegerative disease. Annual review of pharmacology and toxicology, 1996,36: 83-106.

[22]. T. N. Srivastava, Flora Gorakhpurensis, Today and Tomorrow's printers and Publisher. New Delhi.1976.

[23]. B. Subhasree,R. Basker, R. L. Keerthana, R.L. Susan, P. Rajasekaran, Evaluation of antioxidant potential in selected green leafy vegetables. Food Chemistry, 2009,115, 1213-1220.

[24]. C.H.Tang, J. Peng, D. W. Zhen, Z.Chen, Physicochemical and antioxidant properties of Buckwheat (Fagopyrum esculentum Moench) protein hydrolysates. Food Chemistry, 2009,115: 672-678.

[25]. J. A. Vinson, Y. Hao, X. Su, L. Zubik, P. Bose, Phenol antioxidant quantity and quality in foods: fruits. Journal of Agriculture and Food Chemistry2001, 49: 5315-21.

[26]. N. Wang, X.W. Yi, H.F. Yu, B. Dong, S.Y. Qiao, Free radical scavenging activity of Lactobacillus fermentum in vitro and its antioxidative effect on growing-finishing pigs. Journal of Applied Microbiology, 2009, 107: 1140-1148.

[27]. M. Y. Watanabe, T.A. Ohshi, T. Tsushida, Antioxidant compounds from buckwheat (Fagopyrum esculentum Moench) hulls. Journal of Agriculture and Food Chemistry, 1997,45:1039-1044.

[28]. Zielinski H, Kozlowska H.2000. Antioxidant activity and total phenolics in selected cereal grains and their different morphological fractions. Journal of Agriculture and Food Chemistry48:2008-2016.

[29]. K. Zhu, H. Zhou, H. Qian, Antioxidant and free radical -scavenging activities of Wheat germ protein hydrolysates (WGPH) prepared with alcalase. Process Biochemistry, 2006, 41:1296-1302. 